\title{
Measured and Estimated Water Vapor Advection in the Atmospheric Surface Layer
}

\author{
CHAD W. HigGINS \\ Department of Biological and Ecological Engineering, Oregon State University, Corvallis, Oregon \\ ERIC PARDYJAK \\ Department of Mechanical Engineering, University of Utah, Salt Lake City, Utah \\ Martin Froidevaux, Valentin Simeonov, and Marc B. Parlange \\ School of Architecture, Civil and Environmental Engineering, Ecole Polytechnique Federale de Lausanne, \\ Lausanne, Switzerland
}

(Manuscript received 14 November 2012, in final form 21 June 2013)

\begin{abstract}
The flux of water vapor due to advection is measured using high-resolution Raman lidar that was orientated horizontally across a land-lake transition. At the same time, a full surface energy balance is performed to assess the impact of scalar advection on energy budget closure. The flux of water vapor due to advection is then estimated with analytical solutions to the humidity transport equation that show excellent agreement with the field measurements. Although the magnitude of the advection was not sufficient to account for the total energy deficit for this field site, the analytical approach is used to explore situations where advection would be the dominant transport mechanism. The authors find that advection is at maximum when the measurement height is 0.036 times the distance to a land surface transition. The framework proposed in this paper can be used to predict the potential impact of advection on surface flux measurements prior to field deployment and can be used as a data analysis algorithm to calculate the flux of water vapor due to advection from field measurements.
\end{abstract}

\section{Introduction}

In the earth's surface energy budget, the sum of the measured turbulent fluxes are often found to not account for the total available energy (Foken 2008; Foken et al. 2010; Franssen et al. 2010; Higgins 2012; Mauder et al. 2010; Moderow et al. 2009; Oncley et al. 2007; Wilson et al. 2002). While each of these studies provided unique insights, each study also indicated that the advection of water vapor and heat, due to underlying land surface variability, could be a potential energy pathway that is not typically measured. Interpreting advective effects on evaporation measurements becomes paramount in reservoirs and irrigated fields and has been the focus of several studies (Alfieri et al. 2012; Figuerola and Berliner 2005; Hanks et al. 1971; Prueger et al. 1996; Tanny et al. 2008; Zermeño-Gonzalez and Hipps 1997).

Corresponding author address: Chad Higgins, Oregon State University, 116 Gilmore Hall, Corvallis, OR 97331.

E-mail: chad.higgins@oregonstate.edu
Advection also plays an important role in the net ecosystem exchange of $\mathrm{CO}_{2}$ (Etzold et al. 2010; Feigenwinter et al. 2004, 2008; Staebler and Fitzjarrald 2004). The effect of advection on scalar transport efficiency and turbulence spectra was investigated by Kroon and Debruin (1995). The impacts of advection due to topography were addressed by Belcher et al. (2012), and recent efforts have directly measured advection at the field scale using large arrays of instruments (Aubinet et al. 2010; Kochendorfer and Paw U 2011). Although these experiments have elucidated several issues, Kochendorfer and Paw U (2011) found that the advection can be responsible for $15 \%$ of the total water vapor transport; the data density and analysis required for the direct measurement of the advection is not practical for a typical flux measurement or surface energy balance study.

The effect of water vapor advection cannot be neglected over variable land surfaces and is most evident near abrupt changes in land conditions, such as edges of irrigated fields or water bodies (Albertson and Parlange 1999; Baldocchi and Rao 1995; Katul and Parlange 1992; 
Parlange et al. 1993). In this study we measure the advection of water vapor near a lake-land transition using high-resolution Raman lidar measurements of the horizontal atmospheric water vapor distribution. We find that water vapor advection is not sufficient to account for the missing energy in the local energy balance. Next, an analytical description of the horizontal water vapor distribution based on the Sutton solution (Brutsaert 1982; Sutton 1934) is proposed to estimate advection in the absence of spatially distributed measurements. This estimate of the advection is found to compare well to the field measurement. The Sutton advection solution is then used to predict areas that are most likely influenced by advection with respect to field geometry and landscape transitions.

\section{Field experiment}

In the summer of 2008 , four eddy covariance towers were installed near a small lake in northwestern Switzerland (Froidevaux et al. 2013). On each tower, a Campbell Scientific CSAT3 sonic anemometer was coupled to a LI-COR LI-7500 open path gas analyzer and sampled at $20 \mathrm{~Hz}$. On tower 2 , located $\sim 70 \mathrm{~m}$ downwind of the lake edge, a full energy balance was measured. Here, the four-component radiation balance was measured with two pyranometers for incoming and reflected shortwave radiation (Kipp \& Zonen CM21) and two pyrgeometers for downwelling and surfaceemitted longwave radiation (Kipp \& Zonen CG4). The ground heat flux was measured with an array of four Hukseflux HFP01SC soil heat flux plates at 1-cm depth. Finally, a high-resolution Raman lidar was installed and orientated such that the laser beam was less than $30 \mathrm{~cm}$ from the turbulent flux equipment on each tower. The Raman lidar measured the absolute humidity with a time resolution of $1 \mathrm{~s}$ and a spatial resolution of $1.25 \mathrm{~m}$. Raman lidar has been used to measure the surface layer humidity and estimate the evaporation by other authors (Eichinger and Cooper 2007). A full description of the field setup including aerial photographs can be found in Froidevaux et al. (2013) and Higgins et al. (2012).

The turbulent flux measurement towers served two purposes: to measure the sensible and latent heat exchange with the surface and to serve as in situ points of validation for the lidar measurements (Froidevaux et al. 2013). Turbulent flux measurements were computed after the velocity vectors were transformed into flowdefined coordinates with the double-rotation method (Aubinet et al. 2012); the linear trend was removed from each 30-min segment, and segments with error flags or missing values were excluded. Only segments with an average wind angle of attack of less than $45^{\circ}$ with respect

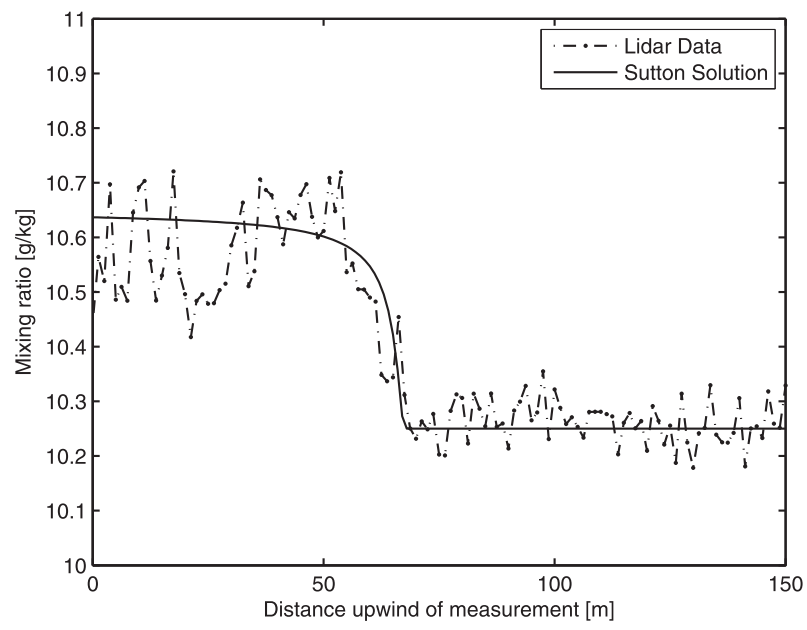

FIG. 1. The atmospheric water vapor concentration jump associated with the flow across a lake-land transition. In this figure, the wind is flowing from the right. The displayed data are a $30-\mathrm{min}$ average of the lidar measurements that were taken on 12 Aug 2008 at 1400 Central European Time (CET). A comparison between the Raman lidar measurements and the Sutton solution for constant height. Atmospheric flow is from right to left.

to the lidar beam were accepted. The 1-s lidar data were averaged over the same 30-min interval. Over the course of the 2-week field experiment, 37 segments of $30 \mathrm{~min}$ were identified that satisfied the criterion in which both the lidar and turbulent flux stations were operational. These data spanned a range of atmospheric stability conditions $-0.4<z / L<0.55$. An example of the typical behavior of the humidity field is presented as the dashed black line in Fig. 1. In Fig. 1, the wind is blowing from right to left; the free surface of the lake is below the right half of the line, while the agricultural field is below the left half. Note the lower absolute humidity above the lake. The data were obtained during the daytime when the lake surface is colder than the land surface.

The full energy budget closure measured at the tower located $\sim 70 \mathrm{~m}$ downstream of the lake edge is presented in Fig. 2. In Fig. 2, the sum of the measured fluxes $(H+L E+G$; sensible + latent + soil heat fluxes, respectively) account for a total of $\sim 80 \%$ of the net radiation. If the advection were a significant pathway for available energy, it should be able to account for a significant portion of this "missing" energy.

\section{Results}

Upon ignoring molecular diffusion, the Reynoldsaveraged water vapor transport equation is given by

$$
\frac{\partial \bar{q}}{\partial t}+\bar{u} \frac{\partial \bar{q}}{\partial x}+\bar{v} \frac{\partial \bar{q}}{\partial y}+\bar{w} \frac{\partial \bar{q}}{\partial z}=-\left(\frac{\partial}{\partial x} \overline{u^{\prime} q^{\prime}}+\frac{\partial}{\partial y} \overline{v^{\prime} q^{\prime}}+\frac{\partial}{\partial z} \overline{w^{\prime} q^{\prime}}\right),
$$




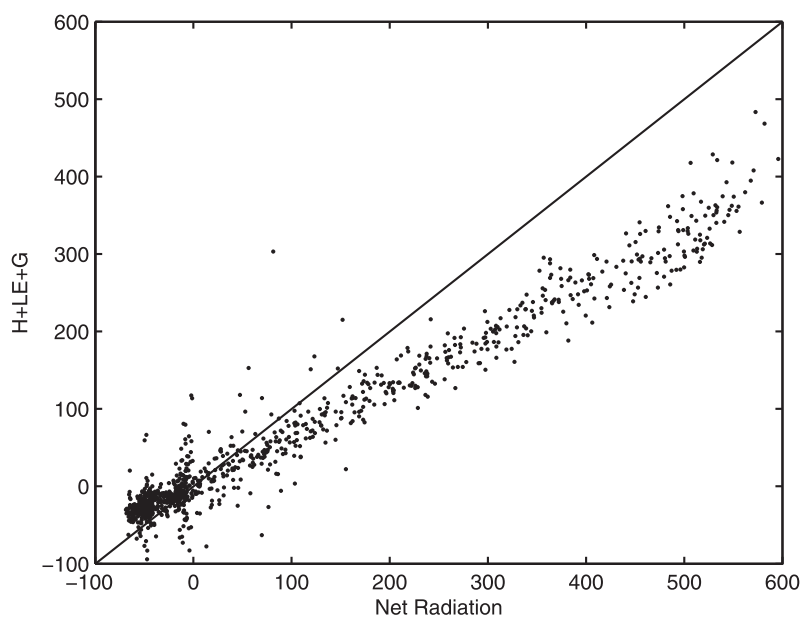

FIG. 2. Energy balance computed near a lake edge showing the typical $20 \%$ missing energy. Note that the overall noise in the flux measurements is $\sim 70 \mathrm{~W} \mathrm{~m}^{-2}$.

where $\bar{q}$ is the time-averaged humidity; $\bar{u}, \bar{v}$, and $\bar{w}$ are the three components of the time-averaged velocity vector; and the primes denote fluctuating quantities. Assuming stationarity $(\partial \bar{q} / \partial t=0)$, a flat surface $(\bar{w}=0)$, spanwise homogeneity $(\partial / \partial y=0)$, horizontal bulk advection that is much greater than horizontal turbulent diffusion $\left(\partial \overline{u^{\prime} q^{\prime}} / \partial x \ll \bar{u} \partial \bar{q} / \partial x\right)$, and that Eq. (1) is expressed in mean flow coordinates $(\bar{v}=0)$, Eq. (1) reduces to

$$
\bar{u} \frac{\partial \bar{q}}{\partial x}=-\frac{\partial}{\partial z} \overline{w^{\prime} q^{\prime}},
$$

where the vertical gradient in the flux is balanced by the horizontal advection (Brutsaert 1982). Note that Eq. (2) also assumes that there are no sources of water vapor above $z=0$. This assumption is violated for forest canopies, and care must be taken in its application. Equation (2) can be integrated in the vertical direction to find both the latent heat flux and advection, as is done elsewhere (Aubinet et al. 2010; Froidevaux et al. 2013; Kochendorfer and Paw U 2011). When the humidity transect is only known at one height, one must assume that the product, $\bar{u} \partial \bar{q}(x) / \partial x$, is not a function of $z$ to move forward with the integral approach. Alternatively, as in the approach taken here, one can assume that the divergence in the measured eddy flux is linear and can simplify the derivative on the right-hand side. Taking either approach results in the following:

$$
c_{v} \bar{u} \frac{\partial \bar{q}}{\partial x} z_{m}=L E_{s}-L E_{m}
$$

where $z_{m}$ is the measurement height, $L E_{m}$ is the latent heat flux measured at the height $z_{m}, L E_{s}$ is the latent heat flux at the land surface, and $c_{v}$ is the latent heat of vaporization. The first term in Eq. (3) is the effect of advection on the measured latent heat flux and is the focus of this study. To estimate advection, a spatially explicit description of the humidity field $\bar{q}(x)$ must be obtained.

Measurements of $\bar{q}(x)$ are provided by the Raman lidar. When they are combined with measurements of the average wind velocity from the sonic anemometers, the advection term in Eq. (3) can be evaluated. However, an appropriate length scale for the humidity gradient $D_{G}$ must still be defined to evaluate the derivative using discrete data: $\partial \bar{q}(x) / \partial x \approx \Delta q / D_{G}$. A local derivative $\left(D_{G}\right.$ approaching 0$)$ would be highly influenced by the signal noise and would not be representative of the flux footprint, defined as the land surface area that contributes to the majority of the measured flux (Finnigan 2004; Hiller et al. 2008; Parlange et al. 1995; Schmid 1997). A second length scale of interest is the horizontal distance from the measurement location to the surface variability or transition $D_{T}$. Together they form a dimensionless group, $D_{G} / D_{T}$, which will be used throughout the paper. In the experimental setup, $D_{T}$ is constant (stationary tower), but the gradient length scale $D_{G}$ is allowed to vary.

To compute the advection term, 30-min data segments' horizontal humidity slices are first averaged in time to find the time-averaged, horizontal humidity transect $[\bar{q}(x)$ in Eq. (3)]. The resulting horizontal transect is differentiated in $x$ with the approximation $\partial \bar{q}(x) / \partial x \approx \Delta q / D_{G}$, and the mean horizontal wind $\bar{u}$ is provided by the sonic anemometer. To perform the most complete analysis of the sensitivity of the computed advection to the choice of length scales, the advection was computed using a range of gradient length scales $\left(D_{G}=70-350 \mathrm{~m}\right)$ for each 30-min-averaged transect. The results are presented as the blue lines in Fig. 3. In Fig. 3, the average value of the advection and the range of values observed during the field experiment (denoted by the feathers in the plot) are shown for each value of $D_{G} / D_{T}$. Note that maximum advection, computed with field data, occurs when the ratio of $D_{G} / D_{T}$ is approximately 1.6. As $D_{G} / D_{T}$ grows, the magnitude of the flux due to advection diminishes, approaching zero. Similarly, as $D_{G} / D_{T}$ approaches zero, the magnitude of the flux also diminishes but does not go to zero. Over the course of the experiment, the maximum flux due to advection for any choice of length scales was $\sim 50 \mathrm{~W} \mathrm{~m}^{-2}$. This value is not sufficient to account for the energy deficit in the surface energy balance, but it cannot be neglected as insignificant.

\section{Sutton advection solution}

As noted in the previous section, the difficulty associated with measurement and prediction of advection is 


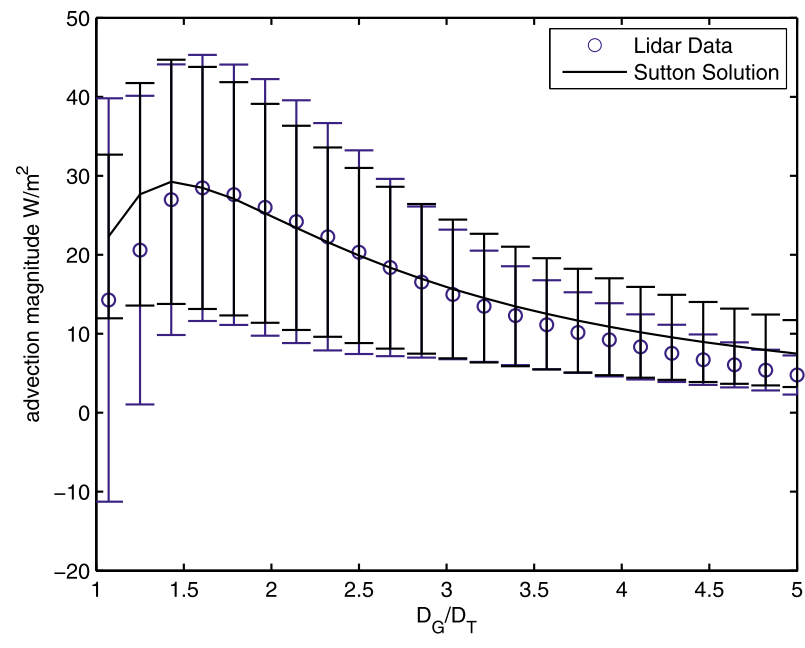

FIG. 3. The measured advection as a function of $D_{G} / D_{T}$. Circles indicate the mean value, and the vertical bars show the range of observed advection at that location over the course of the field experiment. The range represents the full variability ( $\min$ to $\max$ ) in observed advection over the course of the experiment (advections computed for different 30-min segments). A comparison between the advection computed from Raman lidar water vapor measurements (blue lines) and the advection computed analytically with the Sutton solution (black lines) shows that the measured advection matches well with the Sutton estimate of advection regardless of the choice of $D_{G}$. The analytical solution also contains a range of values because it is calculated using the measured $q_{a}, q_{s}$, $q_{a s}$, and $\bar{u}$ for each time segment [see Eq. (7)].

related to the difficulty of obtaining a spatially explicit description of humidity. A spatial distribution of humidity can be obtained experimentally with arrays of instruments (Aubinet et al. 2010; Kochendorfer and Paw U 2011) or remote sensing instrumentation (as in section 3). Similarly, a humidity transect can be estimated with empirical relationships (Itier et al. 1994) through simulation, (Park and Paw U 2004), or by analytically solving the humidity transport equation [Eq. (2)]. A solution to Eq. (2) was first proposed by Sutton (1934) and was reproduced and improved in Brutsaert (1982). The approach of Sutton (1934) is summarized below. A powerlaw behavior for the wind speed as a function of height is assumed, that is, the velocity is only a function of height; thus, it equilibrates immediately after the transition. This assumption is consistent with previous assumptions of $w=0$ and $v=0$ taken in the context of mass conservation:

$$
\bar{u}(z)=\bar{u}_{1}\left(\frac{z}{z_{1}}\right)^{(n / 2-n)} .
$$

Here $n$ is a constant whose value is typically taken as 0.25 . This power-law formulation has been shown to be a good approximation of the typical neutrally stable

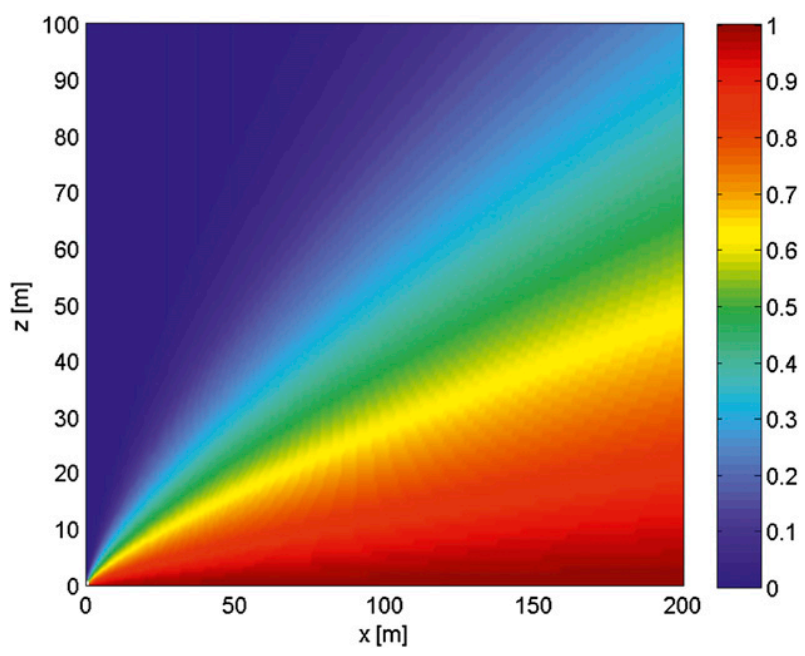

FIG. 4. The theoretical distribution of normalized humidity over stepwise surface change. In this figure, the wind direction is from left to right.

atmospheric velocity profile (Brutsaert and Yeh 1970). The flux of water vapor is modeled using a mixing length approach:

$$
\overline{w^{\prime} q^{\prime}}=A\left(z, u_{*}\right) \frac{\partial q}{\partial z}
$$

Using a single-step change in surface humidity as boundary conditions,

$$
\begin{aligned}
q(0, z) & =q_{a} \\
q(x>0,0) & =q_{s} \\
q(x<0,0) & =q_{a s},
\end{aligned}
$$

a closed form of the humidity distribution can be obtained:

$$
\frac{q(x, z)-q_{a}}{q_{b}-q_{a s}}=\gamma\left(\frac{a m}{u_{*}(2+m-n)^{2}} \frac{z^{2+m-n}}{x}, \frac{m}{2+m}\right),
$$

where $u_{*}$ is the friction velocity, $a$ is a constant whose value is taken as 0.8 in the present study, $m=n /(2-n)$, and $\gamma$ is the well-known partial gamma function defined by

$$
\gamma(s, x)=\int_{x}^{\infty} t^{s-1} e^{-t} d t
$$

A plot of Eq. (7) is seen in Fig. 4. This form is normally used to predict the internal boundary growth (Savelyev and Taylor 2005), where contours of the humidity function provide the boundary layer shape (Brutsaert 

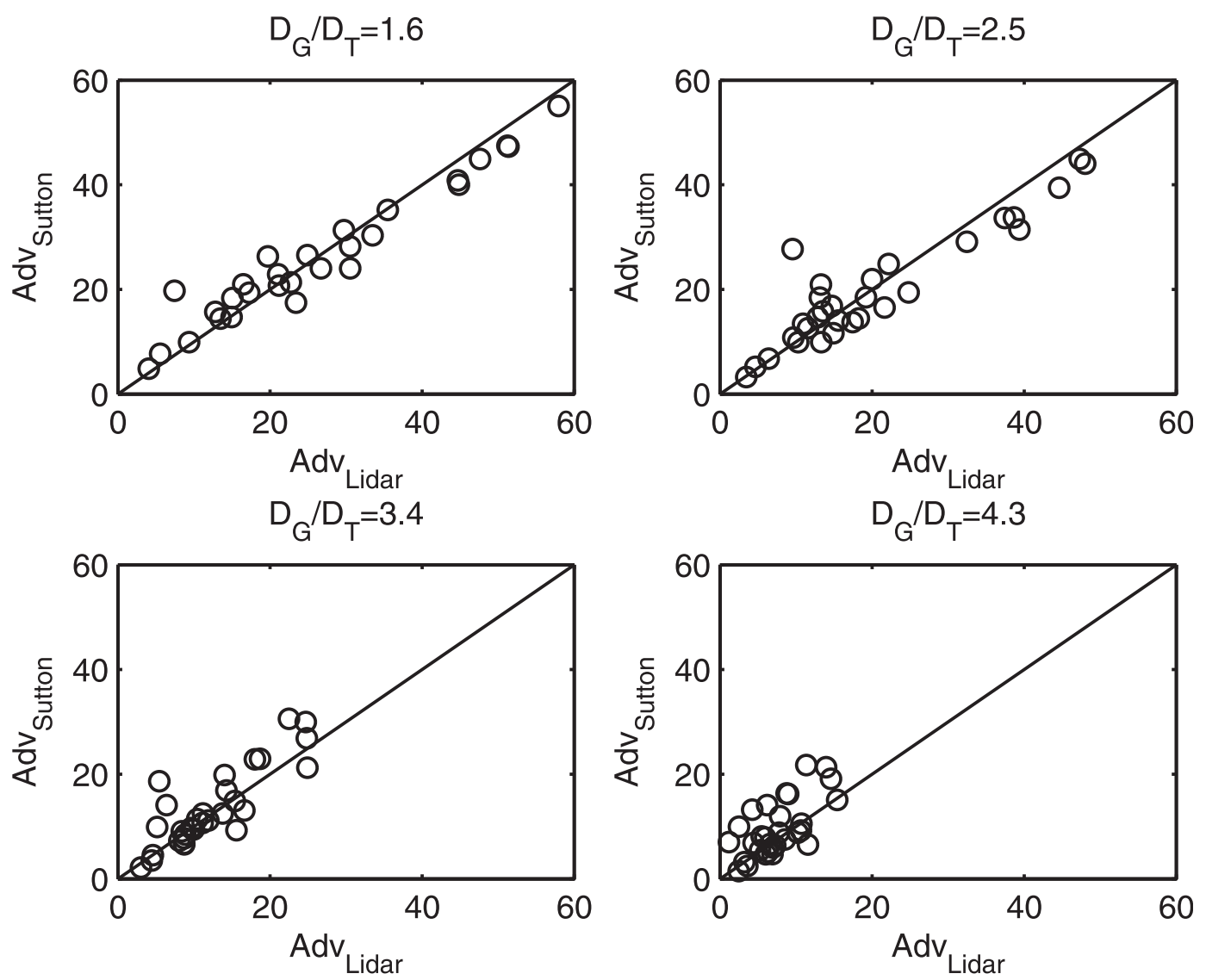

FIG. 5. Direct comparison of estimated and measured values of advection for four values of $D_{G} / D_{T}$. The Sutton solution tends to overestimate advection as $D_{G} / D_{T}$ increases.

1982). The solution given in Eq. (7) can also be readily adapted to the present situation by taking $z$ as a constant, $z=z_{1}$.

A comparison of the Sutton solution (solid black line) with the data (dashed black line) is presented in Fig. 1. To fit the Sutton solution to the data, the following information is necessary: the distance to the upwind land surface transition, the average water vapor concentration at the measurement point, and the average water vapor concentration upstream of the surface transition. Presumably, the average water vapor concentration at the flux measurement point is available, and a field site characterization would provide the necessary distance measurement. Thus, the upstream average humidity is the only additional information required. Since only time-averaged humidity is required, this measurement can be achieved with a single inexpensive humidity probe. Using the Sutton solution, large arrays of instrumentation, expensive remote sensing equipment, or highresolution atmospheric simulations are a priori not required. The fidelity between the Sutton estimates of advection (black lines) and the measured advection (blue lines) is shown in Fig. 3, and an excellent agreement between the estimate of advection and the measured values is found. Sutton tends to overpredict advection as $D_{G} / D_{T}$ becomes large, but this overprediction is less than $10 \mathrm{~W} \mathrm{~m}^{-2}$. Sutton also tends to over predict advection when $D_{G} / D_{T}$ approaches unity, but again this overprediction is small (less than $20 \mathrm{~W} \mathrm{~m}^{-2}$ ). A closer inspection of the advection comparison is presented in Fig. 5, where a direct comparison between estimated and measured advection is presented for individual values of $D_{G} / D_{T}$. Here the full range of advection measurements can be seen (represented by the feathers in Fig. 3). Disagreement here is likely due to the range of stability regimes observed over the course of the experiment. Recall that the Sutton solution does not take these stability effects into account.

The Sutton solution can now be used to investigate the role of advection for any single abrupt transition, and we are free to explore the parameter space to determine the circumstances where advection is most significant. For an abrupt change in surface humidity, the most relevant independent variables are the difference in surface 


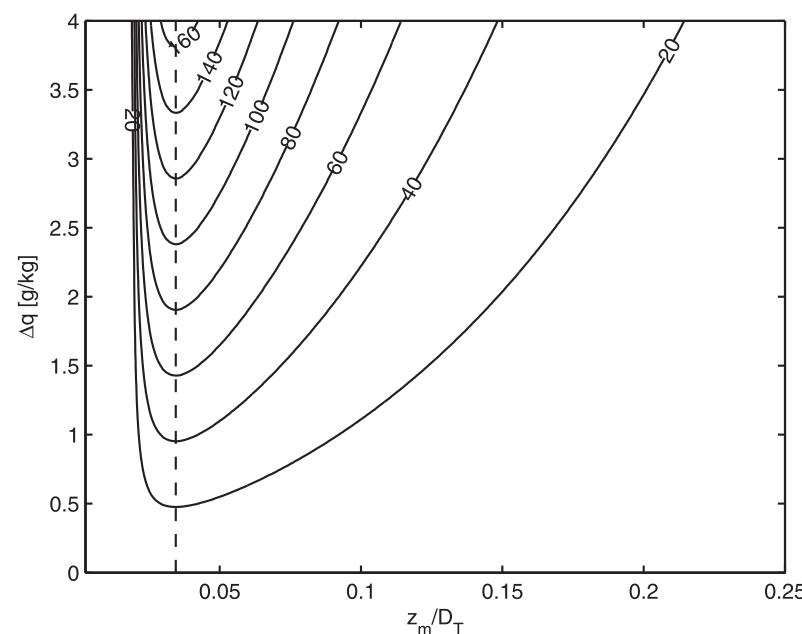

FIG. 6. The theoretical prediction of advection over a range of surface transitions and measurement heights. Note that the maximum advection is observed when $z_{1} / D_{T}=0.036$, indicated by the dashed vertical line.

humidity conditions $\Delta q=q_{b}-q_{a s}$, the measurement height $z_{1}$, and the upwind distance to the land surface transition $D_{T}$. The measurement height is a key parameter in the calculation of the advection term through a direct proportionality in Eq. (3) and as input to the gamma function in the Sutton solution, Eq. (7). The measurement height, along with the atmospheric conditions at the time of measurement, also determines the measurement footprint, which is a natural choice for the length scale of the derivative $D_{G}$. For this hypothetical exploration we assume a typical value of the friction velocity $\left(u_{*}=0.25 \mathrm{~m} \mathrm{~s}^{-1}\right)$, an average wind speed of $1 \mathrm{~m} \mathrm{~s}^{-1}$, and a neutral atmosphere. The flux footprint is then estimated at the $85 \%$ level using the method of Kljun et al. (2004). This footprint length scale is then used to compute the horizontal gradient in Eq. (3). A plot of the magnitude of advection as a function of the surface humidity jump $\Delta q$ and the nondimensional parameter $z_{1} / D_{T}$ is presented in Fig. 6 .

The maximum of advection occurs at $z_{1} / D_{T}=0.036$ for all magnitudes of $\Delta q$. We also observe that advection is a minimum for $z_{1} / D_{T}<0.02$, which is in accordance with the rule-of-thumb 50:1 fetch to measurement ratio height typically used for eddy flux measurements. This is important from a planning perspective as the placement of a flux measurement tower can significantly change the expected contribution of advection. As an example, for the current field geometry, $2.5-\mathrm{m}$ measurement height and $67 \mathrm{~m}$ to the lake edge, $z_{1} / D_{T}=0.037$, nearly at the advection maxima. Moving the tower $38 \mathrm{~m}$ and lowering the measurement height to $2 \mathrm{~m}$ would reduce $z_{1} / D_{T}$ to less than 0.02 . Figure 6 can also be used to determine reasonable values of expected advection, not only to consider possible sources of error in energy budget closure, but also to be used as a means to evaluate evaporation measurements with limited fetch such as lakes and fields.

\section{Conclusions}

Raman lidar was used in conjunction with traditional eddy covariance measurements to determine the contribution of water vapor advection to the surface energy balance. The measured energy flux due to advection was not sufficient to close this missing energy gap. Nevertheless, advection cannot be neglected as an important energy pathway.

The humidity transport equation was solved analytically for the case of a stepwise change in surface conditions, leading to the well-known Sutton solution. This solution was used to develop an estimate of advection and was vetted with the Raman lidar measurements. Using the analytical form, the effect of advection can be estimated with minimal added cost and effort. The analytical form also provides a valuable planning tool for tower placement and experimental design. It is shown that the maximum amount of advection occurs at a fixed position relative to the measurement height and field geometry $\left(z_{1} / D_{T}=0.036\right)$ regardless of the land surface transition strength. Furthermore, if field experiments are designed such that $z_{1} / D_{T}<0.02$, the effects of advection on the evaporation measurements could be minimized.

Acknowledgments. This work was funded in part by the Swiss National Science Foundation.

\section{REFERENCES}

Albertson, J. D., and M. B. Parlange, 1999: Natural integration of scalar fluxes from complex terrain. Adv. Water Resour., 23, 239-252, doi:10.1016/S0309-1708(99)00011-1.

Alfieri, J. G., and Coauthors, 2012: On the discrepancy between eddy covariance and lysimetry-based surface flux measurements under strongly advective conditions. Adv. Water Resour., 50, 62-78, doi:10.1016/j.advwatres.2012.07.008.

Aubinet, M., and Coauthors, 2010: Direct advection measurements do not help to solve the night-time $\mathrm{CO}_{2}$ closure problem: Evidence from three different forests. Agric. For. Meteor., 150, 655-664, doi:10.1016/j.agrformet.2010.01.016.

— T. T. Vesala, and D. Papale, 2012: Eddy Covariance: A Practical Guide to Measurement and Data Analysis. Springer, 438 pp.

Baldocchi, D. D., and K. S. Rao, 1995: Intra-field variability of scalar flux densities across a transition between a desert and an irrigated potato field. Bound.-Layer Meteor., 76, 109-136, doi:10.1007/BF00710893.

Belcher, S. E., I. N. Harman, and J. J. Finnigan, 2012: The wind in the willows: Flows in forest canopies in complex 
terrain. Annu. Rev. Fluid Mech., 44, 479-504, doi:10.1146/ annurev-fluid-120710-101036.

Brutsaert, W., 1982: Evaporation into the Atmosphere: Theory, History, and Applications. Kluwer, 299 pp.

—_, and G. T. Yeh, 1970: A power wind law for turbulent transfer computations. Water Resour. Res., 6, 1387-1391, doi:10.1029/ WR006i005p01387.

Eichinger, W. E., and D. I. Cooper, 2007: Using lidar remote sensing for spatially resolved measurements of evaporation and other meteorological parameters. Agron. J., 99, 255-271, doi:10.2134/agronj2005.0112S.

Etzold, S., N. Buchmann, and W. Eugster, 2010: Contribution of advection to the carbon budget measured by eddy covariance at a steep mountain slope forest in Switzerland. Biogeosciences, 7, 2461-2475, doi:10.5194/bg-7-2461-2010.

Feigenwinter, C., C. Bernhofer, and R. Vogt, 2004: The influence of advection on the short term $\mathrm{CO}_{2}$-budget in and above a forest canopy. Bound.-Layer Meteor., 113, 201-224, doi:10.1023/ B:BOUN.0000039372.86053.ff.

— , and Coauthors, 2008: Comparison of horizontal and vertical advective $\mathrm{CO}_{2}$ fluxes at three forest sites. Agric. For. Meteor., 148, 12-24, doi:10.1016/j.agrformet.2007.08.013.

Figuerola, P. I., and P. R. Berliner, 2005: Evapotranspiration under advective conditions. Int. J. Biometeorol., 49, 403-416, doi:10.1007/s00484-004-0252-0.

Finnigan, J., 2004: The footprint concept in complex terrain. Agric. For. Meteor., 127, 117-129, doi:10.1016/j.agrformet.2004.07.008.

Foken, T., 2008: The energy balance closure problem: An overview. Ecol. Appl., 18, 1351-1367, doi:10.1890/06-0922.1. , and Coauthors, 2010: Energy balance closure for the LITFASS2003 experiment. Theor. Appl. Climatol., 101, 149-160, doi:10.1007/ s00704-009-0216-8.

Franssen, H. J. H., R. Stockli, I. Lehner, E. Rotenberg, and S. I. Seneviratne, 2010: Energy balance closure of eddycovariance data: A multisite analysis for European FLUXNET stations. Agric. For. Meteor., 150, 1553-1567, doi:10.1016/ j.agrformet.2010.08.005.

Froidevaux, M., C. W. Higgins, V. Simeonov, P. Ristori, E. Pardyjak, I. Serikov, and M. B. Parlange, 2013: A new Raman lidar to measure water vapor in the atmospheric boundary layer. $A d v$. Water Resour., 51, 345-356, doi:10.1016/j.advwatres.2012.04.008.

Hanks, R. J., L. H. Allen, and H. R. Gardner, 1971: Advection and evapotranspiration of wide-row sorghum in central GREAT PLAINS. Agron. J., 63, 520-527, doi:10.2134/ agronj1971.00021962006300040002x.

Higgins, C. W., 2012: A-posteriori analysis of surface energy budget closure to determine missed energy pathways. Geophys. Res. Lett., 39, L19403, doi:10.1029/2012GL052918.

— M. Foidevaux, V. Simeonov, and M. Parlange, 2012: The importance of scale for Taylor's hypothesis. Bound.-Layer Meteor., 143, 379-391, doi:10.1007/s10546-012-9701-1.

Hiller, R., M. J. Zeeman, and W. Eugster, 2008: Eddy-covariance flux measurements in the complex terrain of an Alpine valley in Switzerland. Bound.-Layer Meteor., 127, 449-467, doi:10.1007/s10546-008-9267-0.

Itier, B., Y. Brunet, K. J. McAneney, and J. P. Lagouarde, 1994: Downwind evolution of scalar fluxes and surface-resistance under conditions of local advection. Part I. A reappraisal of boundary conditions. Agric. For. Meteor., 71, 211-225, doi:10.1016/0168-1923(94)90012-4.
Katul, G. G., and M. B. Parlange, 1992: A Penman-Brutsaert model for wet surface evaporation. Water Resour. Res., 28, 121-126, doi:10.1029/91WR02324.

Kljun, N., P. Calanca, M. W. Rotachhi, and H. P. Schmid, 2004: A simple parameterisation for flux footprint predictions. Bound.-Layer Meteor., 112, 503-523, doi:10.1023/ B:BOUN.0000030653.71031.96.

Kochendorfer, J., and K. T. Paw U, 2011: Field estimates of scalar advection across a canopy edge. Agric. For. Meteor., 151, 585594, doi:10.1016/j.agrformet.2011.01.003.

Kroon, L. J. M., and H. A. R. Debruin, 1995: The Crau field experiment: Turbulent exchange in the surface-layer under conditions of strong local advection. J. Hydrol., 166, 327-351, doi:10.1016/0022-1694(94)05092-C.

Mauder, M., R. L. Desjardins, E. Pattey, and D. Worth, 2010: An attempt to close the daytime surface energy balance using spatially-averaged flux measurements. Bound.-Layer Meteor., 136, 175-191, doi:10.1007/s10546-010-9497-9.

Moderow, U., and Coauthors, 2009: Available energy and energy balance closure at four coniferous forest sites across Europe. Theor. Appl. Climatol., 98, 397-412, doi:10.1007/ s00704-009-0175-0.

Oncley, S. P., and Coauthors, 2007: The Energy Balance Experiment EBEX-2000. Part I: Overview and energy balance. Bound.Layer Meteor., 123, 1-28, doi:10.1007/s10546-007-9161-1.

Park, Y. S., and K. T. Paw U, 2004: Numerical estimations of horizontal advection inside canopies. J. Appl. Meteor., 43, 1530-1538, doi:10.1175/JAM2152.1.

Parlange, M. B., G. G. Katul, M. V. Folegatti, and D. R. Nielsen, 1993: Evaporation and the field scale soil-water diffusivity function. Water Resour. Res., 29, 1279-1286, doi:10.1029/93WR00094.

_ W. E. Eichinger, and J. D. Albertson, 1995: Regional-scale evaporation and the atmospheric boundary-layer. Rev. Geophys., 33, 99-124, doi:10.1029/94RG03112.

Prueger, J. H., L. E. Hipps, and D. I. Cooper, 1996: Evaporation and the development of the local boundary layer over an irrigated surface in an arid region. Agric. For. Meteor., 78, 223 237, doi:10.1016/0168-1923(95)02234-1.

Savelyev, S. A., and P. A. Taylor, 2005: Internal boundary layers: I. Height formulae for neutral and diabatic flows. Bound.Layer Meteor., 115, 1-25, doi:10.1007/s10546-004-2122-z.

Schmid, H. P., 1997: Experimental design for flux measurements: Matching scales of observations and fluxes. Agric. For. Meteor., 87, 179-200, doi:10.1016/S0168-1923(97)00011-7.

Staebler, R. M., and D. R. Fitzjarrald, 2004: Observing subcanopy $\mathrm{CO}_{2}$ advection. Agric. For. Meteor., 122,139-156, doi:10.1016/ j.agrformet.2003.09.011.

Sutton, O. G., 1934: Wind structure and evaporation in a turbulent atmosphere. Proc. Roy. Soc. London, 146A, 701-722, doi:10.1098/ rspa.1934.0183.

Tanny, J., and Coauthors, 2008: Evaporation from a small water reservoir: Direct measurements and estimates. J. Hydrol., 351, 218-229, doi:10.1016/j.jhydrol.2007.12.012.

Wilson, K., and Coauthors, 2002: Energy balance closure at FLUXNET sites. Agric. For. Meteor., 113, 223-243, doi:10.1016/S0168-1923(02)00109-0.

Zermeño-Gonzalez, A., and L. E. Hipps, 1997: Downwind evolution of surface fluxes over a vegetated surface during local advection of heat and saturation deficit. J. Hydrol., 192, 189 210, doi:10.1016/S0022-1694(96)03108-3. 